\title{
A espacialização dos parques e a dinâmica da produção, apropriação e valorização do espaço urbano em Ribeirão Preto (SP)
}

The spatialization of parks and the dynamics of production, appropriation and enhancement of urban space in Ribeirão Preto - São Paulo

La spacialisation des parcs et les dynamiques de production, appropriation et amélioration de l'espace urbain à Ribeirão Preto - São Paulo

\section{Marcos Antônio Silvestre Gomes}

\section{OpenEdition}

Journals

Edição electrónica

URL: http://journals.openedition.org/espacoeconomia/181

DOI: 10.4000/espacoeconomia. 181

ISSN: 2317-7837

Editora

Núcleo de Pesquisa Espaço \& Economia

Refêrencia eletrónica

Marcos Antônio Silvestre Gomes, «A espacialização dos parques e a dinâmica da produção, apropriação e valorização do espaço urbano em Ribeirão Preto (SP) », Espaço e Economia [Online], 2 | 2013, posto online no dia 09 março 2013, consultado o 19 abril 2019. URL : http:// journals.openedition.org/espacoeconomia/181 ; DOI : 10.4000/espacoeconomia.181

Este documento foi criado de forma automática no dia 19 Abril 2019.

(c) NUPEE 


\section{A espacialização dos parques e a dinâmica da produção, apropriação e valorização do espaço urbano em Ribeirão Preto (SP)}

The spatialization of parks and the dynamics of production, appropriation and enhancement of urban space in Ribeirão Preto - São Paulo

La spacialisation des parcs et les dynamiques de production, appropriation et amélioration de l'espace urbain à Ribeirão Preto - São Paulo

Marcos Antônio Silvestre Gomes

\section{Introdução}

1 Os parques são elementos da paisagem urbana que se inscrevem no espaço construído. Ocupam área específica, demarcada no espaço, sobre a qual se realiza trabalho, obras que permitem o seu uso efetivo. Este trabalho, obras, de produção do parque, relaciona-se à dinâmica mais ampla de reprodução da cidade. Constituindo um objeto politicamente definido, não é neutro na paisagem, mas altera a característica do lugar, do espaço onde está inserido.

Como diz Santos, "a partir do reconhecimento dos objetos na paisagem, e no espaço, somos alertados para as relações que existem entre os lugares. Essas relações são respostas ao processo produtivo no sentido largo, incluindo desde a produção de mercadorias à produção simbólica" (SANTOS, 2004, p. 72).

Os parques são equipamentos públicos pelo fato de, em geral, terem sido delimitados em terras de propriedade municipal, estadual ou federal, ou seja, em terras públicas. No entanto, dependendo da localização, são apropriados privadamente por classes e interesses específicos. 
Historicamente, os parques estão relacionados ao usufruto de classes específicas na Europa, no século XIX, quando a cidade industrial, carregada de seus "males", provocava, naqueles que tinham rendas mais elevadas, a procura pelo campo, como lugar de refúgio, paz, "natureza". Assim, o arquétipo de parque tal qual se propagou pelas cidades de todo o mundo surgiu, de certo modo, da prática de tratamento paisagístico nas imediações das mansões senhoriais no campo, sobretudo, no século XVIII (WILLIAMS, 1989).

No Brasil, os primeiros parques são do século XIX, no Rio de Janeiro e em São Paulo. A implantação de muitos parques nessas, e em outras cidades, inscreve-se no contexto de profundas mudanças, sobretudo nas áreas centrais, em fins do século XIX e início do século XX. Neste período, inúmeros parques foram criados em cidades brasileiras como elementos que contribuíram para o embelezamento da "cidade moderna", possibilitando a utilização e o aproveitamento de terrenos alagadiços de várzeas, fundos de vale e áreas junto ao mar. A implantação desses projetos provocou mudanças no processo de produção das cidades, interferindo nos preços das terras, das edificações e na dinâmica de ocupação do espaço urbano.

Desde fins da década de 1970 os parques urbanos no Brasil, comumente, ocupam áreas destinadas como de uso comum ${ }^{1}$ nos loteamentos, conforme a Lei Federal 6.766/79 ${ }^{2}$. No entanto, a distribuição e implantação dos equipamentos públicos nessas áreas competem aos órgãos municipais, que as realiza segundo seus interesses. Além disso, as áreas onde se implantam os parques podem ser desapropriadas pelo poder público, ou doadas pela iniciativa privada. As desapropriações ocorrem através de lei municipal, mediante indenização, e envolvem acordos/negociações entre ambas as partes.

7 Na cidade de Ribeirão Preto-SP, objeto desta análise, parques foram implantados, desde a década de 1960, segundo interesses e estratégias diferenciadas, evidenciando o processo contraditório de produção do espaço, em especial quando se analisa a atuação do Estado, em âmbito municipal. Muitos discursos são produzidos e disseminados ressaltando características como lazer, qualidade de vida, "natureza" etc., no entanto, uma análise criteriosa desses equipamentos no espaço urbano demonstra um processo conflituoso e desigual, contrariando os discursos propalados.

Este processo de criação e implantação de parques, sobretudo, respaldado em um discurso em torno da preservação da natureza, em pauta pelos organismos internacionais, como a ONU, evidencia, por um lado, a atuação de gestões públicas, não simplesmente no intuito de criar, delimitar espaços de lazer, de proteção da natureza, mas de projetar-se como empreendedoras, com interesses políticos; de outro, as estratégias de grupos imobiliários para auferirem renda diferencial ${ }^{3}$ no espaço urbano, uma vez que estes parques agregamse como fator positivo ao lugar, bairro, zona e, por conseqüência, provocam valorização imobiliária.

9 Alguns parques implantados a partir da década de 1990 em Ribeirão Preto, como o "Prefeito Luiz Roberto Jábali" e "Dr. Luís Carlos Raya", tornaram-se equipamentos importantes que contribuíram na dinamização e valorização da zona Sul da cidade, conforme aponta Gomes (GOMES, 2009). Estes parques fazem parte de um conjunto de estratégias (avenidas ajardinadas, boulevards, shopping centers etc.) que, implantado nas áreas onde mora a população com maiores rendimentos, contribuiu para a maior valorização dos imóveis em relação às outras parcelas da cidade.

10 Em outros setores urbanos ${ }^{4}$ não ocorreu o mesmo processo. Parques públicos como o Augusto Ruschi e o Cláudio Franco Lima (ver Mapa 1), embora criados por lei, não foram 
efetivamente implantados, do ponto de vista da infraestrutura. Além disso, não apresentam significativo importante da fauna e flora local. São espaços vazios não utilizados, efetivamente, para lazer e/ou contemplação/conservação da natureza. Dessa forma, a criação de inúmeros parques na cidade de Ribeirão Preto não se justifica pela necessidade de conservação da fauna e flora, uma vez que estes não dispõem de nada a preservar. Mesmo assim, são utilizados nos discursos públicos como forma de engrossar os índices ilusórios de verde por habitante, tecnicamente endossados como medidores de "qualidade de vida".

11 Em Ribeirão Preto, embora existam muitas áreas denominadas parques, como demonstrado a seguir, efetivamente poucas foram implantadas. Foram criadas por lei, mas não desempenham função de parque, especialmente quando se localizam na periferia pobre da cidade.

\section{Espacialização dos parques urbanos e os processos de valorização desigual do espaço urbano}

Constata-se que houve uma evolução expressiva no número de parques em Ribeirão Preto, nas últimas décadas. Em 1998 havia 11 (onze) áreas regulamentadas por lei. Já em 2004, o número de parques na cidade se elevou para 17 (dezessete), sendo que 9 (nove) não se encontravam efetivamente implantados (Quadro 1). Estes parques foram criados por lei municipal, mas, em alguns casos, foram implantados em parceria com a iniciativa privada, como ocorreu com os parques Prefeito Luiz Roberto Jábali e Dr. Luís Carlos Raya. A estes dois parques dar-se-á ênfase maior, nesta discussão, pela importância que assumem no processo de valorização desigual do espaço em Ribeirão Preto.

13 Para a Prefeitura Municipal de Ribeirão Preto ${ }^{5}$, consideram-se implantadas as áreas que "contenham equipamentos de lazer, passeio, iluminação, mobiliário, ponto de água, vegetação existente natural e/ou implantada, gramados ou ajardinamento e tratamento paisagístico, todos com manutenção periódica".

14 Semi-implantadas são as áreas que, "apesar de não serem efetivamente implantadas, contenham algum tipo de infra-estrutura e/ou manutenção (pública ou privada)". Esta infraestrutura pode ter sido implantada pela comunidade, como, por exemplo, um campo de futebol.

15 As áreas não-implantadas correspondem àquelas que, "mesmo contendo vegetação natural, [...] não há infra-estrutura, equipamentos sociais, implantação de qualquer tipo de vegetação e manutenção periódica da vegetação já existente".

Quadro 1

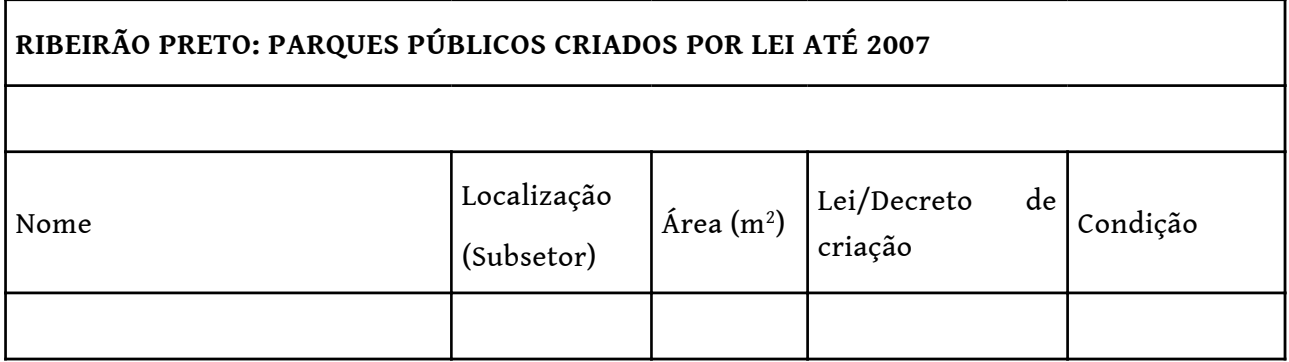




\begin{tabular}{|c|c|c|c|c|}
\hline Parque Augusto Ruschi & $\mathrm{N}-10$ & $66.682,49$ & $7337 / 1996$ & $\begin{array}{l}\text { Não } \\
\text { implantado }\end{array}$ \\
\hline Parque Tom Jobim & $\mathrm{N}-06$ & $63.448,54$ & $7068 / 1995$ & Implantado \\
\hline $\begin{array}{l}\text { Parque Ecológico Orestes Lopes } \\
\text { de Camargo }\end{array}$ & N-06 & $19.922,76$ & $6907 / 1994$ & $\begin{array}{l}\text { Não } \\
\text { implantado }\end{array}$ \\
\hline $\begin{array}{lll}\text { Parque } & \text { Linear } & \text { Ulisses } \\
\text { Guimarães } & & \end{array}$ & N-01/08 & $275.250,50$ & $6709 / 1993$ & Implantado \\
\hline $\begin{array}{l}\text { Parque José Maria Morgade } \\
\text { Miranda }\end{array}$ & N-01 & $54.948,00$ & $7020 / 1995$ & $\begin{array}{l}\text { Não } \\
\text { Implantado }\end{array}$ \\
\hline $\begin{array}{l}\text { Parque Municipal Morro de São } \\
\text { Bento }\end{array}$ & N-01 & $250.880,00$ & $\begin{array}{l}476 / 1995 \\
262 / 1999\end{array}$ & Implantado \\
\hline $\begin{array}{l}\text { Parque } \quad \text { Ecológico } \\
\text { Verde }\end{array}$ & L-09 & $105.055,65$ & $8382 / 1999$ & $\begin{array}{l}\text { Semi- } \\
\text { implantado }\end{array}$ \\
\hline $\begin{array}{l}\text { Parque Municipal da Mata do } \\
\text { Jardim Palmares }\end{array}$ & L-07 & $90.673,01$ & L.C. $1691 / 2004$ & $\begin{array}{l}\text { Não } \\
\text { Implantado }\end{array}$ \\
\hline $\begin{array}{l}\text { Parque Prefeito Luiz Roberto } \\
\text { Jábali }\end{array}$ & L-03 & $138.700,25$ & L.C. $1009 / 2000$ & Implantado \\
\hline Parque Linear Sérgio Motta & $\begin{array}{l}\text { L-03/L-06/ } \\
\text { S-03 }\end{array}$ & $179.468,00$ & $351 / 1999$ & $\begin{array}{l}\text { Semi- } \\
\text { implantado }\end{array}$ \\
\hline Parque Francisco Prestes Maia & $0-02$ & $12.485,25$ & $1686 / 1965$ & Implantado \\
\hline Parque Maurílio Biagi & $0-02$ & $196.522,31$ & $4233 / 1982$ & Implantado \\
\hline $\begin{array}{l}\text { Parque Ecológico Cláudio } \\
\text { Franco Lima }\end{array}$ & $0-07$ & $12.322,00$ & $617 / 1996$ & $\begin{array}{l}\text { Não } \\
\text { Implantado }\end{array}$ \\
\hline $\begin{array}{l}\text { Parque Ecológico e Botânico } \\
\text { Ângelo Rinaldi }\end{array}$ & $0-07$ & $182.986,17$ & $620 / 2000$ & $\begin{array}{l}\text { Semi- } \\
\text { implantado }\end{array}$ \\
\hline Roberto de Melo Genaro & S-01 & $11.722,00$ & $496 / 1995$ & $\begin{array}{l}\text { Não } \\
\text { Implantado }\end{array}$ \\
\hline Parque Dr. Luís Carlos Raya & S-07 & $39.560,29$ & $\begin{array}{l}10208 / 2004 \\
425 / 2004\end{array}$ & Implantado \\
\hline $\begin{array}{l}\text { Parque Fernando de Freitas } \\
\text { Monteiro }\end{array}$ & S-05 & $68.605,59$ & $8142 / 1998$ & Implantado \\
\hline
\end{tabular}

FONTE: PREFEITURA MUNICIPAL DE RIBEIRÃO PRETO-SP/DEPARTAMENTO DE GESTÃO AMBIENTAL 2007.

ORg. MARCOS ANTÔNIO SILVESTRE GOMES. 
O Mapa 1 permite visualizar a espacialização dos parques urbanos em Ribeirão Preto, implantados, semi-implantados e não implantados.

17 A criação de parques urbanos em Ribeirão Preto, embora tenha se iniciado, oficialmente, a partir de 1965, com o Parque Francisco Prestes Maia, tem sido mais marcante após a década de 1990, quando 11 (onze) parques foram regulamentados por lei, conforme demonstrado no Quadro 1. Um dos aspectos que justifica este aumento significativo no número de parques, não só em Ribeirão Preto, mas em outras cidades, está relacionado ao conjunto de estratégias discursivas que envolve a questão ambiental. Sobretudo a partir da década de 1990 a ideia do desenvolvimento sustentável se tornou proeminente nas agendas políticas globais e locais.

Os parques Francisco Prestes Maia e Maurílio Biagi, ambos criados anteriormente à década de 1990, constituem-se em espaços abertos adjacentes à área central (Figura 1). 0 primeiro, de dimensão pequena (cerca de $12 \mathrm{mil} \mathrm{m}^{2}$ ), se assemelha a uma praça, circundando o Pronto Socorro Municipal. Constitui-se no espaço mais antigo da cidade denominado de parque. $O$ segundo circunda a Câmara Municipal de Ribeirão Preto e é separado do primeiro pelo Terminal Municipal Rodoviário. Neste parque tem-se observado esforços constantes em ampliar a arborização.

Mapa 1 - Ribeirão Preto: Distribuição espacial dos parques urbanos - 2007

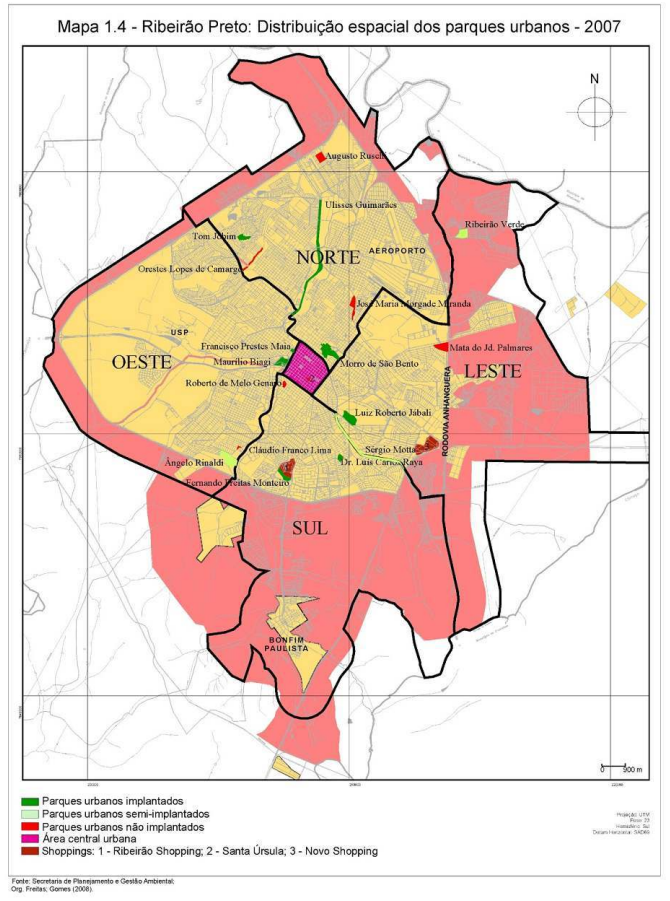

FONTE : SECRETARIA de PLANEJAMENTO E GESTÃo AMBIENTAL. ORgANIZAdO PELO AUTOR. 
Figura 1 - Vista aérea dos parques Maurílio Biagi (à direita) e Francisco Prestes Maia (à esquerda), no ano de 2004

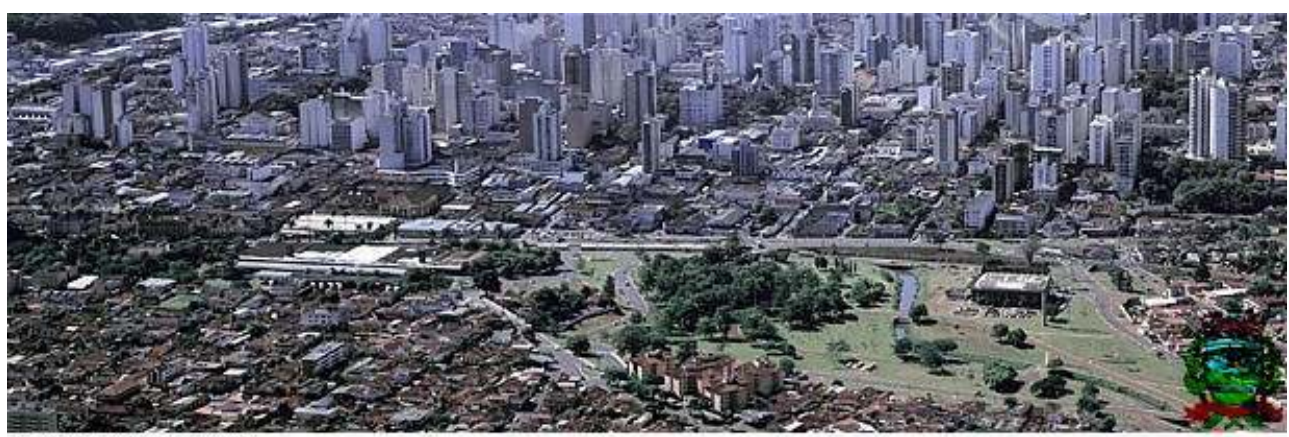

Parque Maurilio Biagi

FONTE: HTTP://WWW.RIBEIRAOPRETO.SP.gOV.BR ACESSO EM AgOSTO DE 2007.

19 Entretanto, em termos funcionais e de infraestrutura, o Parque Municipal Morro de São Bento, também margeando a área central urbana, embora denominado por lei em 1995, constitui um dos espaços mais antigos criados com a função de lazer e conservação ambiental em Ribeirão Preto. Foi adquirido pela municipalidade, no ano de 1907, através da compra da Chácara Olympia, e implantado oficialmente, como Bosque Municipal ${ }^{6}$, em 1937, na gestão de Fábio Barreto, passando, posteriormente, por processos de melhoramentos na sua infraestrutura. O Parque Municipal Morro de São Bento abriga, além de trecho de mata nativa, que forma originalmente o bosque, dois complexos (um esportivo e um cultural), totalizando uma área de 250.880 metros quadrados ${ }^{7}$ (Figura 2).

Convém salientar que, em Ribeirão Preto, os parques não se encontram bem distribuídos ao longo da malha urbana, de forma que favoreça seu uso por todas as parcelas da população. Na maioria dos casos não dispõem da infraestrutura necessária ao seu uso. São classificados como semi-implantados pela Prefeitura, mas não oferecem condições mínimas de uso, como é o caso do Parque Ecológico Ribeirão Verde (Figura 3), localizado na zona Leste.

21 Nos poucos casos em que os parques são efetivados, as prioridades são estabelecidas pelo poder público que, em geral, justifica a grande quantidade de parques não implantados pela ausência de recursos financeiros.

Figura 2 - Vista panorâmica do Parque Municipal Morro de São Bento no final da década de 1990. A área verticalizada na parte inferior da imagem indica o centro da cidade.

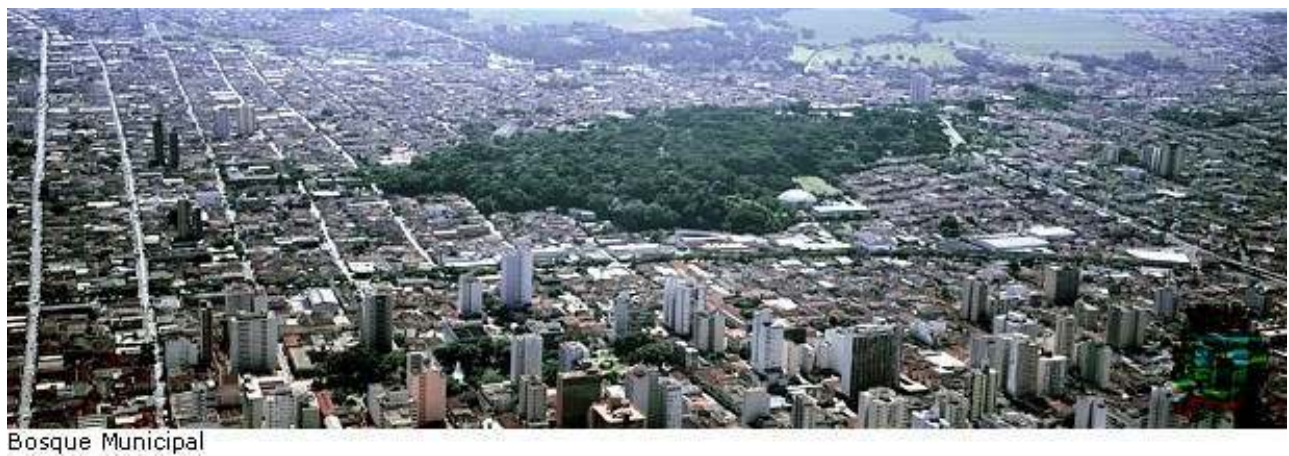

FONTE: HTTP://WWW.RIBEIRAOPRETO.SP.gOV.BR. ACESSO EM AgOSTO DE 2007. 
Figura 3 - Parque Ecológico Ribeirão Verde (2008)

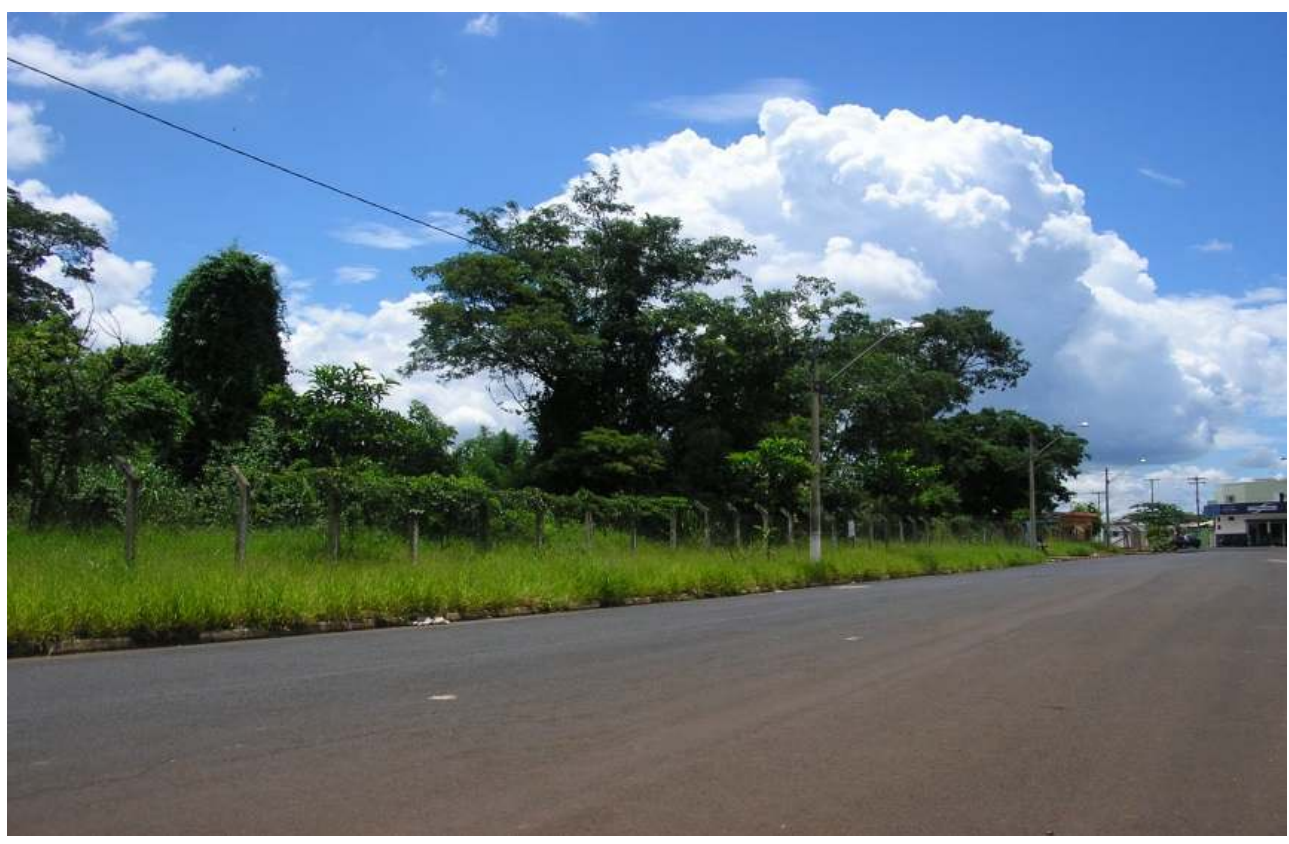

FOTO DO AUTOR

22 Há casos também em que o parque consta no cadastro da Prefeitura como implantado, mas não recebeu nenhum tipo de infraestrutura ou cuidados com a vegetação. Nesta situação se encontra, por exemplo, o Parque Linear Ulisses Guimarães, na zona Norte (Figura 4). Este parque não oferece nenhum atrativo para o seu uso. Localiza-se em uma área habitada por famílias de baixa renda que, em geral, dispõem de poucas opções de lazer. Como se trata de um fundo de vale, nem mesmo as márgens do Córrego que o corta receberam plantio de árvores, o que deveria se constituir em uma medida importante, pois contribuiria para a formação de uma mata ciliar. 


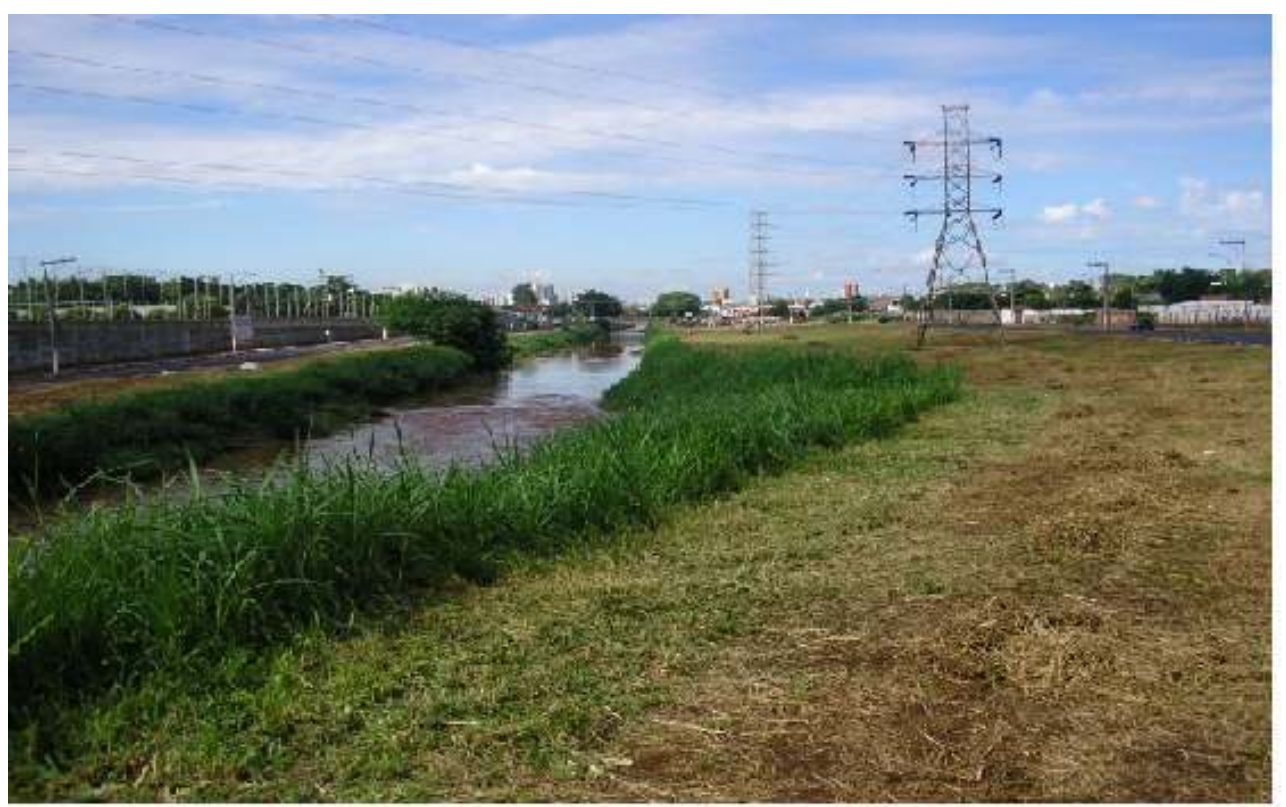

FOTO DO AUTOR.

Muitos parques se localizam em áreas e sob condições questionáveis de implantação. Diante dos discursos do poder público e dos grupos imobiliários, que ressaltam as vantagens dos parques para toda a cidade, constata-se que os espaços mais bem equipados estão localizados em áreas de crescente valorização imobiliária, geralmente pouco acessíveis às camadas de baixa renda. No eixo Sul-sudeste, para onde se tem dirigido a expansão urbana, conforme diretrizes do Plano Diretor Municipal (Lei Complementar $\mathrm{n}^{\circ}$ 501/95), e que corresponde à área de maior valorização fundiária, como demonstrado por Gomes (2009), foram criados e implantados pelo poder público os dois mais equipados parques da cidade: Parque Prefeito Luiz Roberto Jábali, no ano 2000, e o Parque Dr. Luís Carlos Raya, em 2004.

Estes parques contribuíram no processo de valorização da zona Sul. Foi verificado que os terrenos próximos aos referidos parques apresentam preços mais elevados do que outros nos mesmos bairros onde se localizam, proporcionando renda diferencial elevada, confirmando que os parques representam uma forma de valorização imobiliária. Ou seja, enquanto o preço do $\mathrm{m}^{2}$ do solo na zona Sul, entre 1995 e 2008, aumentou em mais de $300 \%$, custando em média $\mathrm{R} \$ 300,00$ no final do período; nas demais zonas esse aumento foi menos expressivo, e o preço do $\mathrm{m}^{2}$ custava em média $\mathrm{R} \$ 100,00$, com exceção do Setor Leste, onde alguns bairros que fazem limite com a zona Sul apresenta preços superiores.

Da mesma forma, em 2008, o preço do $\mathrm{m}^{2}$ do solo no entorno imediato do Parque Dr. Luis Carlos Raya era em média $\mathrm{R} \$ 300,00$, enquanto em outras partes do mesmo loteamento onde está implantado custava $\mathrm{R} \$ 220,00$. No caso do Parque Luiz Roberto Jabali o $\mathrm{m}^{2}$ nas suas imediações custava em média $\mathrm{R} \$ 250,00$, em terrenos mais distantes do parque o preço médio era de $\mathrm{R} \$ 165,00$.

26 As áreas onde foram implantados estes parques passaram para a municipalidade de forma distinta. A correspondente ao Parque Prefeito Luiz Roberto Jábali resultou de desapropriação, enquanto a do Parque Dr. Luís Carlos Raya se insere no percentual de 
áreas de uso comum do loteamento Jardim Botânico, como obriga a Lei 6.766/79. Em ambos os parques, uma característica é comum às áreas onde foram implantados: resultam de antiga exploração de basalto no município (Figura 5). Estas áreas foram incorporadas à malha urbana devido ao crescimento da cidade e permaneceram sem nenhum uso, mas como reserva de valor, por mais de vinte anos, desde que foram encerradas as atividades econômicas na década de 1970. Através de processos diferentes foram transformadas em parques.

27 Ao analisar as características do uso do solo nas áreas de antigas pedreiras, que atualmente correspondem aos parques supracitados, observa-se que em outros períodos havia um "aproveitamento" da terra-mercadoria, mas também meio de produção, para a exploração do basalto. No período atual, estas áreas, aparentemente obsoletas no espaço urbano, mudam de característica com a criação de uma nova paisagem, diferenciando o lugar. Este lugar, uma vez reproduzido, passa a ser apropriado e consumido, não mais pela exploração econômica dos seus recursos, mas pela capacidade de oferecer uma atratividade relacionada ao lazer.

28 As áreas de antigas pedreiras no espaço urbano podem ser compreendidas como aquilo que Gottdiener (GOTTDIENER, 1997) denomina de capital parado do passado. Transformadas em parques, estas áreas tornam-se "novas raridades" no espaço urbano. Como terra pública, não entram no mercado de compra e venda, mas alteram o preço das terras nas imediações e conferem novo valor à cidade e ao lugar.

29 Estas áreas, enquanto espaços de exploração de riqueza no passado, ao significar, em momento específico, uma barreira à reprodução do capital, são transformadas em espaços de valorização do capital, decorrentes de interesses públicos e privados, sendo uma de suas consequências, finalidades a alteração e o aumento do preço de troca da terra urbana. Enquanto espaços "obsoletos", as antigas pedreiras são incorporadas ao processo de produção do espaço urbano, integrando-se à lógica de reprodução do capital. Constituem estratégias para o mercado imobiliário local, agregando-se, enquanto equipamentos públicos, à dinâmica de valorização imobiliária da zona Sul-sudeste da cidade de Ribeirão Preto.

30 A implantação de parques em áreas de antigas pedreiras é expressão do processo de destruição criativa tal como diz Harvey (HARVEY, 1998). Representa a destruição de formas pretéritas que não interessam para a acumulação de capital, que tem estagnada a renda diferencial da terra; implica a reprodução e reapropriação do espaço, altera as características morfológicas, a mudança do ritmo e da forma de extração da riqueza. Destrói-se o espaço anteriormente produzido para, então, recriá-lo, conferindo novos usos que contribuem para a reprodução do capital, para o aumento da renda da terra urbana, em especial da renda diferencial.

31 Como as áreas de antigas pedreiras (parques) não mais significam a extração direta da riqueza (terra, basalto), foram modificadas, reproduzidas, e assim contribuem para o incremento, produção e circulação da riqueza no mercado imobiliário. 


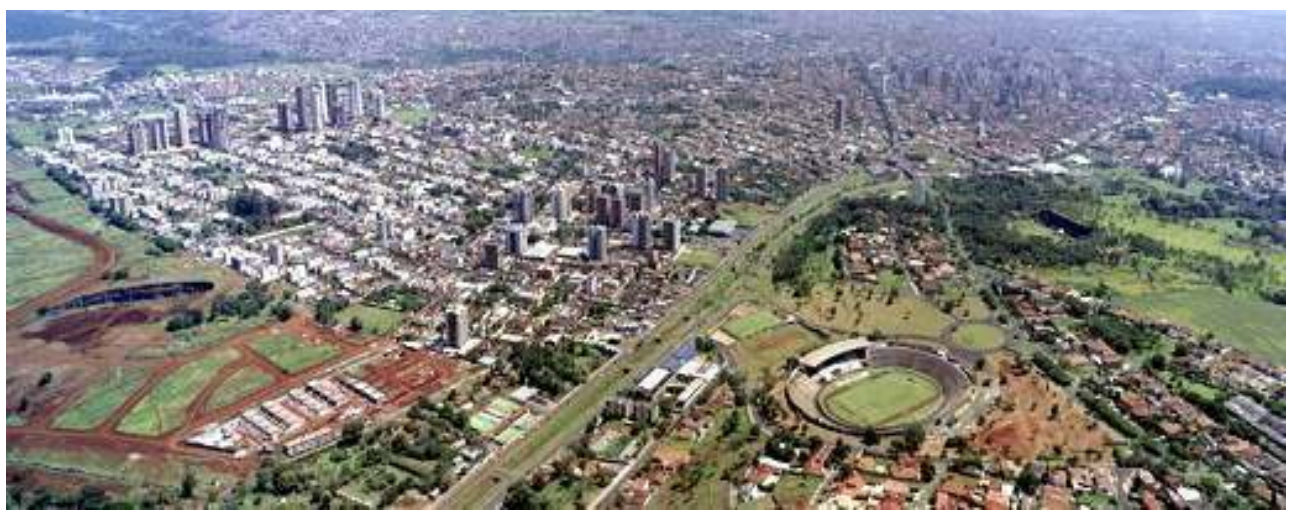

À DIREITA, O PARQUe PREFEITO LUIZ ROBERTO JÁbALI; À ESQUERDA, CAVA DA PEDREIRA ONDE FOI IMPLANTADO O PARQUE DR. LUÍS CARLOS RAYA. NO ALTO, À ESQUERDA, EDIFÍCIOS DA AVENIDA JOÃO FIÚZA (2005), UM IMPORTANTE EIXO DE VALORIZAÇÃO DA ZONA SUL.

FONTE: SECRETARIA DE PLANEJAMENTO E GESTÃo AMBIENTAL dE RIBEIRÃo PRETO. ORg.: MARCOS ANTÔNIO SILVESTRE GOMES.

Os parques Prefeito Luiz Roberto Jábali e Dr. Luís Carlos Raya são representativos da produção espacial em Ribeirão Preto, onde os equipamentos públicos têm sido implantados nas áreas em que se aloja a população de maior renda e a que se confere um maior valor ao solo urbano. Dessa forma, se tornam notáveis na cidade não só pela dimensão que assumem como espaços de lazer, mas pela localização em áreas de crescente valorização imobiliária e pela projeção imputada pelo poder público. Os parques se tornaram símbolos de gestões públicas municipais como forma de aumentar a competitividade do município.

33 As gestões administrativas de Luiz Roberto Jábali e Gilberto Sidney Maggioni na Prefeitura Municipal de Ribeirão Preto foram encerradas, respectivamente, no ano de 2000 e 2004, com a inauguração dos parques Prefeito Luiz Roberto Jábali e Dr. Luís Carlos Raya. À época, os discursos propalados pelo poder público enalteciam as qualidades estéticas, infraestruturais e ecológicas destes espaços.

34 Jornais locais, à época da inauguração dos parques, anunciavam a entrega destes à população, destacando-os como um fator positivo para toda a cidade. Um deles, ao se reportar ao Parque Dr. Luís Carlos Raya estampou como título: “Área nobre de Ribeirão ganhará outro parque". Assim, divulgou a importância do parque e destacou a sua localização como uma característica positiva para a cidade, sem atentar para a ampliação das desigualdades socioespaciais urbanas decorrentes da concentração de investimentos públicos em áreas específicas da cidade.

35 A implantação de infraestrutura (estradas, asfalto, luz etc.) e de equipamentos públicos (escolas, postos de saúde, praças, parques etc.) altera o uso e o preço da terra urbana. Assim, a implantação de parques, mesmo sem a adequada infraestrutura, mobiliário e vegetação nas áreas ocupadas pela população de baixa renda, também pode alterar o preço da terra, mas nesta análise se enfatizou os parques que alteraram significativamente o preço da terra por estarem vinculados aos interesses imobiliários especulativos.

36 Embora em número significativo (17) para um município de 547.417 habitantes (IBGE, 2007), a maior parte dos parques de Ribeirão Preto que dispõem de infraestrutura, que 
permite o uso efetivo, esta concentrada no eixo Centro-sul-sudeste. Contraditoriamente, a distribuição da população em números absolutos em Ribeirão Preto e a densidade populacional por setores censitários (IBGE, 2000), apontam a maior parte da população concentrada nas zonas Norte e Oeste, em geral as mais carentes em áreas de lazer, como praças e parques. Juntas, essas zonas concentram cerca de $2 / 3$ da população do município e metade dos domicílios.

37 Em relação à renda, constata-se que há uma concentração das camadas de rendimentos mais elevados nas zonas Sul e Leste, o que evidencia uma contradição entre a implantação de equipamentos públicos nessas áreas e a carência desses equipamentos nas zonas Norte e Oeste, concentradoras da população de menor poder aquisitivo.

38 Estas constatações apontam que o poder público municipal, ao criar e implantar espaços, como parques e praças, nos setores onde se localizam os interesses imobiliários, dirigidos às camadas de mais alta renda da cidade, contribui para o aumento do preço dos terrenos, loteamentos e edificações, consolidando o eixo Sul-sudeste de Ribeirão Preto como uma área estrategicamente rendosa do ponto de vista imobiliário. Nesse eixo, estão instalados os três shopping centers da cidade, equipamentos urbanos que contribuem para o aumento do preço do solo nessas áreas (ver mapa 1).

\section{Considerações finais}

39 Este artigo destacou a análise dos parques como equipamentos públicos no espaço urbano, demonstrando que a forma como estão distribuídos em Ribeirão Preto não atende às necessidades de toda a população.

40 Os parques mais bem equipados e que recebem cuidados constantes pelo poder público localizam-se no eixo Sul-Sudeste da cidade. Foram criados através de parcerias públicoprivadas, cujo interesse predominante era a valorização fundiária dos loteamentos aos quais fariam ou fazem parte, e não a conservação da natureza. São alegorias, simulacros, no espaço e no tempo.

41 Na periferia pobre, as áreas destinadas aos parques, em sua maioria, permanecem sem atrativos, usos que justifiquem a sua denominação. Há casos em que a população implanta, a seu modo, algumas improvisações, como campo de futebol, bancos de madeira, árvores etc, evidenciando a negligência do poder público.

42 Em Ribeirão Preto, gestores públicos e agentes privados sintonizam o discurso do "verde" no espaço urbano. Por um lado, vendem a imagem da cidade, seus parques, praças, áreas arborizadas etc. como fundamental para a qualidade de vida de todos e como sinônimo de preocupação ambiental. Por outro, concentram suas ações em parcelas específicas da cidade, restringindo os usos dos "espaços verdes" às camadas que podem pagar para morar nas imediações destas áreas e/ou para elas podem se deslocar.

o discurso ambiental, ao ser incorporado como estratégia desses agentes, no processo de produção do espaço urbano, impõe a compra e venda da imagem do parque. Estes equipamentos, voltando-se ao discurso do lazer, da recreação, do tempo livre, da qualidade ambiental e de vida e da estética urbana, inserem-se também no processo de produção e mercantilização da natureza, tornando-se um elemento simbólico no imaginário social. 


\section{BIBLIOGRAFIA}

BRASIL. Lei n. 6.766, de 19 de dezembro de 1979. Dispõe sobre o Parcelamento do Solo Urbano e dá outras providências. Texto atualizado em 30 de março de 2001, de acordo com a Lei 9.785, de 29 de janeiro de 1999.

GOMES, Marcos A. S. Parques urbanos de Ribeirão Preto-SP: Na produção do espaço, o espetáculo da natureza. Tese (Doutorado em Geografia). Universidade Estadual de Campinas: IGE. São Paulo, 2009.

GOTTDIENER, Mark. A produção social do espaço urbano. 2a edição. São Paulo: Edusp, 1997.

HARVEY, David. Condição pós-moderna: uma pesquisa sobre as origens da mudança cultural. 7a ed. São Paulo: Edições Loyola, 1998 (1989).

IBGE. Censo 2000. Instituto Brasileiro de Geografia e Estatística.

IBGE. Instituto Brasileiro de Geografia e Estatística. Disponível: http://www.ibge.gov.br. Acesso em 2007 e 2008.

RIBEIRÃO PRETO. Lei Complementar n. 501, de 31 de outubro de 1995. Dispõe sobre a instituição do Plano Diretor do Município de Ribeirão Preto e dá outras providências.

SANTANA, Paola V. A mercadoria verde: a natureza. In: DAMIANI, Amélia, CARLOS, Ana F. A. (orgs.). O espaço no fim de século: a nova raridade. São Paulo: Contexto, 1999.

SANTOS, Milton. A natureza do espaço: técnica e tempo, razão e emoção. 4a ed. São Paulo: Edusp, 2004.

WILLIAMS, Raymond. o campo e a cidade na história e na literatura. São Paulo: Cia das Letras, 1989.

\section{NOTAS}

1. A Lei $\mathrm{n}^{\circ}$ 3.071, de 1 de janeiro de 1916, em seu Artigo 65, define os bens públicos como: 1- De uso comum do povo, tais como mares, rios, estradas ruas e praças; II- De uso especial, tais como os edifícios ou terrenos aplicados a serviços ou estabelecimento federal, estadual ou municipal; III-Dominiais, isto é, os que constituem o patrimônio da União, dos Estados, ou dos Municípios, como objeto de direito pessoal, ou real de cada uma dessas entidades.

2. Esta lei dispõe sobre o parcelamento do solo urbano e dá outras providências. Na redação original desta lei, previa-se a destinação de $35 \%$ da gleba para áreas públicas (sistema viário, áreas verdes e institucionais etc.). Este percentual passou a ser fixado pelos municípios, de acordo com a Lei 9.785/99. Em Ribeirão Preto foi fixado entre 40 e $50 \%$ da área total do loteamento (Lei 2.157/2007).

3. Para esta análise, importa afirmar que a renda diferencial resulta da aplicação/investimento de capital em determinada área, que cria melhorias permanentes, culminando no "sobrelucro que provém das vantagens de terrenos melhor localizados" (RODRIGUES, 1988, p. 89). Para aprofundamento sobre renda da terra, consulte Harvey (HARVEY, 1990). 
4. De acordo com o Decreto Municipal no 333, de 26 de dezembro de 1983, a cidade é dividida em setores e subsetores. São os setores: Norte, Sul, Leste e Oeste, conforme o Mapa 1.

5. Plano Diretor de Arborização Urbana, Relatório $N^{\circ}$ 01, 2003, não publicado, fornecido pela Secretaria Municipal de Planejamento e Gestão Ambiental (2004).

6. Em 1948 passou a ser denominado Bosque Municipal Fábio Barreto, de acordo com a Lei ${ }^{\circ} 61$, de 22 de novembro.

7. Informações obtidas em documento denominado "Histórico da fundação do Bosque Municipal”, s/d, elaborado por Tânia Cristina Registro, disponível no Arquivo Público e Histórico de Ribeirão Preto.

\section{RESUMOS}

Este trabalho analisa os parques urbanos em Ribeirão Preto-SP. Demonstra que, historicamente estão distribuídos de maneira irregular no espaço urbano. Em geral, não constituem espaços de "preservação", elementos neutros na paisagem, como se pregam nos discursos públicos e privados. São alegorias, simulacros no espaço e no tempo. Um tipo de equipamento urbano que altera a dinâmica de produção, reprodução do espaço e de valorização do lugar.

This article analyzes the urban parks in Ribeirão Preto, São Paulo, and its unequal distribution in urban space. Generally urban parks aren't spaces of preservation as it is preached by publics and private discourses. They are allegories and simulacra, a type of urban equipment that changes the dynamics of production, reproduction and valorization to the space.

Cet article analyse les parcs urbains à Ribeirão Preto, São Paulo. Sous le plan historique, on peut voir qu'ils sont distribués de façon inégale sur l'espace. Au contraire des discours publiques et privés, les parcs ne sont pas des espaces de préservation, mais des allégories, des simulacres; une sorte d'équipement urbain capable de modifier la production, la reproduction et la valorisation de l'espace.

\section{ÍNDICE}

Mots-clés: parcs, espace urbain, valorisation de la nature, inegalités socio-spatiales, Ribeirão Preto

Palavras-chave: parques, espaço urbano, valorização da natureza, desigualdades sócio-espaciais, Ribeirão Preto

Keywords: parks, urban space, valorisation of nature, social and spatial inequalities, Ribeirão Preto 
AUTOR

MARCOS ANTÔNIO SILVESTRE GOMES

Doutor em Geografia pela Universidade Estadual de Campinas (UNICAMP). Professor Adjunto do Departamento de Geografia da UFF-Campos dos Goytacazes. Email: msilvestre@id.uff.br 